\title{
Un Cantar Hallado en Tucumán
}

$H_{\mathrm{N}}$ su Cancionero popular de Tucumán, tomo I, el eminente folklorista argentino Juan Alfonso Carrizo, dice en una nota al pie de la página 290: ${ }^{1}$ "Mi amigo, el distinguido escritor salteño don Miguel Solá me dictó una canción compuesta de saetillas, hallada en unos papeles viejos pertenecientes al gobernador de Salta, don Miguel Otero, sin fecha. Lleva al pie una firma que parece decir Juan Antonio Vera y no sabría opinar si ese señor fué autor o mero copista. Hela aquí :

1. Mira, mira pecador 2 que si vives en pecado puedes anochecer bueno y amanecer condenado.

2. Mira que es breve tu vida y que vas muy a la posta, vas caminando a la muerte, piénsalo bien que te importa.

3. Triste, turbado y confuso, temeroso y aun temblando entre batallas y penas estarás agonizando.

4. Piénsalo bien que te importa para que mudes tu vida, $y$ lo hagas cuanto antes porque ya estás de partida.

5. Cuando agonizando estés, y roncándote ya el pecho, $y$ con la vela en la mano -. ¿qué quisieras habet hecho?
6. Presto llegará este lance porque la vida es muy corta, no lo tengas en olvido piénsalo bien que te importa.

7. ¿Qué pálido y qué medroso estarás amortajado, sin tener ya de este mundo nada de lo que has juntado!

8. Piénsalo bien que te importa y mira que sepultado serás tierra, podre y huesos, $y$ has de quedar olvidado.

9. Si en el juicio de Dios aun el más santo ha temblado, jcómo! pecador no tiemblas con tanto como has pecado.

10. Piénsalo bien que te importa pues si vives descuidado podrás ser por tu descuido en el juicio condenado. 
11.

están allá en el infierno

echando a Dios maldiciones

$y$ rabiando en fuego eterno.

12. Piénsalo bien, que te importa, para del fuego librarte; y si no 10 piensas puedes sin pensarlo condenarte.

13. Mira bien y considera la gloria que prevenida está para aquellos que sirven a Dios en la vida.

14. Sus murallas primorosas admiran con sus riquezas, y con su hermosura forman y hechizan con su belleza.

15. Sus calles tienen por losas preciosas piedras brillantes, que brillan aun más que el oro y que los finos diamantes.
16. Nunca es noche y siempre es día en esta hermosa ciudad, porque la luz que la alumbra es de Díos la claridad.

17. Músicas suenan en ella de los angélicos coros que a Dios cantan alabanzas muy dulces y muy sonoros.

18. Qué será la vista bella de los ángeles y santos que más que el sol resplandecen siendo sin númetos, tantos!

19. Qué será ver a la Virgen más bizarra y más hermosa, que los ángeles y santos, y más que ellos gloriosa!

20. Y cuando el alma vea a Jesús flor de las flores. deliciando con fragancia y esparciendo resplandores".

Esta canción, que, por lo visto, es una composición erudita más bien que folklórica, se halla también en Nuevo México. En 1892, el Padre J. B. Ralliere de la parroquia de Tomé publicó una versión incompleta, titulada "La Muerte", con las palabras "Entonación mejicana" entre paréntesis debajo del título, "con lo que daba a entender que se cantaba con una melodía del pueblo nuevomexicano. La versión que publicó el Padre Ralliere contiene solamente doce saetillas. Faltan los números 13-20. La estrofa número 11, que carece del primer verso en la versión tucumana, está completa en la versión del Padre Ralliere. Este primer verso reza así:

\section{"En perpetuos alaridos."}

He encontrado este cantar, también, en un manuscrito de Arroyo Hondo, en el norte de Nuevo México, y en dos manuscritos del sur del Estado de Colorado, el uno de Cerritos y el otro de Antonito. ${ }^{4}$ Las tres versiones contienen veinte y siete saetas cada una, es decir, siete más que la argentina y quince más que la del Padre Ralliere. Las dos de Colorado están copiadas con una ortografía bastante có- 
rrecta $y$, al parecer, han sido sacadas de otras copias, posiblemente de alguna copia impresa, tal vez de algún devocionario. La versión nuevomexicana, sin embargo, está escrita en una ortografía muy original. Esta versión o fué copiada de un manuscrito muy malo o fué escrita de memoria o al dictado. A continuación doy una copia fiel de esta versión:

1. Mira, mira, pecador, 5 que, si bibes en pecado, puedes anocheser vueno llay maneser condenado.

2. Mira que breve es tu vida y que bas muy a la posta caminando así a [hacia] la muerte, piénsalo bien que te importa.

3. Triste, turbado y confuso, temerozo y aun temblando entre batallas $y$ penas estarás agonizando.

4. Piénsalo bien que te importa para que enmiendes tu bida y lo hagas cuanto antes porque llay estás de partida.

5. Cuando agonisando estés y roncándote llay el pecho $y$ con la bela en la mano, ¿qué quisieras aber echo?

6. Presto llegará este lanze porque la bida es muy corta; no lo tengas en olbido, piénzalo vien que te inporta.

7. Qué pálido y qué medrozo estarás amortajado, sin tener llay deste mundo nada de cuanto as juntado.

8. Piénsalo vien que te importa, y mira que sepultado entre tierra, podre y huesos has de quedar olbidado.
9. Si en el juicio de Dios aun el más santo a temblado, ¡cómo, pecador, no tiemblas, con tanto como as pecado!

10. Piénsalo bien que te importa, pues si bibes descuidado, podrás ser por tu descuido en el juicio condenado.

11. En perpetos alaridos están allay en el infierno echando a Dios maldiciones y rabiando en fuego eterno.

12. Piénsalo bien que te importa para el fuego librarte y si no lo piensas puedes sin pensarlo condenarte.

13. Mira vien y concidera la gloria que prebenida está para aquellos que sirben a Dios en la Bida.

14. Sus murallas primorozas addemiran con su riqueza $y$ con su hermosura pasman y echisan con su belleza.

15. Sus calles tienen por lozas presiosas piedraș brillantes que brían aun más que el oro $y$ que los finos de amantes.

16. Nunca es noche, siempre es día en esta hermosa ciudad porque la luz que la alumbra es de Dios la claridad. 
17. Músicas suenan en ellay de los ángeles y santos que a Dios cantan alabanzas muy dulces y muy sonotas.

18. ¿Qué será la bista bella de los ángeles y santos que más quel sol resplandesiente siendo sin número tanto?

19. ¿Qué será ber a la Virgen más bizarra y más hermoza que los ángeles y santos y más que todos gloriosa?

20. Y que cuando el alma vea a Jesús flor de las flores deliciando con fragancia $y$ es por siendo [esparciendo] resplandores,

21. Y cuando le eche tus brazos $y$ le diga con dulsura:

"Ven, vendito de mi Padre y gosa de mi hermosura:

22. Ven para siempre a gosar de mi dulce companía donde para siempre ya todo es goso llay legria [y alegría]."

23. ¿Ho! ¡Cuán contento y gososa y cuán llena de dulsura estará el alma en la gloria biendo de Dios la hermosura!

24. Si esta dicha y esta gloria no te empeñas en ganarla, teniéndola en ta mano, te quedates $\sin$ gosarla.

25. Despierta y olley mi boz y mira lo:que te exsorta y teniéndolo presente, piénsalo bien que te importa.

26. Estudia todos los días en este despertador y aborreserás los bisios aun ciendo muy pecacior.

27. Si cuidadoso 10 hases $y$ lo concideras bien, conseguiras vuena bida y guena muerte también. Fin.

E1 hallarse versiones de este cantar en la Argentina así como en Nuevo México prueba que ni la versión del señor Carrizo es de origen argentino ni las versiones nuevomexicanas son de origen nuevomexicano. Podemos decir casi con toda seguridad que lo mismo la versión argentina que las nuevomexicanas tuvieron sit origen en España. Está claro, también, que la canción fué transmitida a ambas regiones en forma impresa. La correspondencia casi exacta entre las diferentes. versiones lo testifica. El hecho de que la versión tucumana tiene solamente veinte estrofas se debe, sin duda, a un error de omisión, pues si se examina la estrofa número 20 , desde luego se ve que la idea está incompleta y si examinamos la versión nuevomexicana, averiguaremos que la idea no se completa hasta el fin de la estrofa número 23.

En cuanto a la versión del Padre Ralliere, es posible que él conociera la versión completa pero que omitiera las últimas quince 
estrofas de propósito, por ser la canción demasiado larga en la forma original.

Las cuatro versiones de este cántico que tengo en mi posesión, incluso el ejemplar de la Colección de cánticos espirituales del Padre Ralliere, pertenecían a miembros de la Cofradía de Nuestro Padre Jesús, cofradía de penitentes que existe en Nuevo México y en el sur de Colorado. El citado cántico pertenece a una colección de más de doscientos cánticos religiosos que los nuevomexicanos llaman "alabados" y que yo recogí entre el pueblo de habla española de Nuevo México y de Colorado. Estos cánticos, algunos de los cuales son verdaderos romances religiosos de origen español, los canta el pueblo en los velorios. Los cantan también los penitentes durante sus ceremonias, especialmente durante la cuaresma $y$, en particular, durante la Semana Santa. Más tarde se publicarán estas canciones anónimas que han venido a ser propiedad del pueblo. Se publicarán también las melodías que les sirven de acompañamiento, melodías, al parecer, muy antiguas y probablemente de origen español.

JUAN B. RAEL, Stanford University.

NOTAS

1. Cancionero popular de Tucumán, Juan Alfonso Carrizo, Buenos Aires, A. Baiocco y Cía. Editores, 1937, tomo I, 558.

2. La numeración de las saetas no figura en la versión del señor Carrizo. He numerado yo cada estrofa para que se pueda hacer fácilmente una comparación con las versiones que cito más adelante.

3. Colección de cánticos espitituales, recogidos por el Rev. P. J. B. Ralliere, Las Vegas, 1892. $333 \mathrm{pp}$.

4. La recopilación de estas versiones y otros materiales folklóricos en mi posesión, la llevé a cabo bajo los auspicios de la American Philosophical Society de Philadelphia, Pennsylvania.

5. La puntuación es mía. 
